\title{
Fuzzy comprehensive evaluation on the government purchase pension service quality management
}

\author{
Wang XuJia \\ School of Management \\ Xi'an University of Architecture and Technology \\ Xi'an 710055, P. R. China \\ wangxujia@163.com
}

\author{
Lai $\mathrm{Yu}$ \\ School of Management \\ Xi'an University of Architecture and Technology \\ Xi'an 710055, P. R. China \\ Laiyu_209@163.com
}

\begin{abstract}
This paper is combined with successful cases of the Chinese typical city governments purchase pension service, and on this basis, analyzing the present situations advantages and disadvantages of social organizations provide pension service quality supervision and evaluation in actual operation. The developed countries mature management experience for reference, using the theory of system engineering to construct suitable for Chinese government purchase pension service quality management effectiveness index system from four aspects, which is the life care services, physical and mental health services, leisure and recreation services and safety and hygiene services, and to evaluate each factor priority of the index system's criterion layer and the index layer with quantitative fuzzy comprehensive method. Evaluation result for guarantee elderly pension life quality, improve allocation efficiency of the public service resource, and perfect the pension service management processes, thus promoting the development of social organizations, expanding public management theory and research method has a very important practical and theoretical significance.
\end{abstract}

Keywords- Government purchase; Pension service; Quality management; NSFDSS; Comprehensive evaluation;

\section{INTRODUCTION}

In recent years, as for the provision of the urban aging population pension service, it has been gradually transformed the existing government unified public service supply mode into government purchasing society organization pension service mode. This change has promoted the transformation of government functions, reduced the financial cost, promoted the development of social organizations, and improved the service diversification and specialization. But at the same time, when using this model in the actual operation, the governments are often difficult to make

Supported by the key discipline construction projects special funds of Shaanxi Province (E08001)

Supported by the special fund of key research base of philosophy and Social Science in Shaanxi Province universities (DA08046)

Supported by the special fund of characteristics discipline of philosophy and social science in Shaanxi Province universities: Research on real estate technology economics and management in Shaanxi Province (E08005) Supported by the Xi'an university of architecture and technology Youth Fund: Study of pension service government procurement mechanism of Shaanxi province (QN1229) effective evaluation and quality supervision of the implementation of the contract after they has signed contracts with service providers. Throughout the investigation results show that, for the production and the provision of pension services, the government and social organization generally lack the scientific system of the evaluation and supervision system.

At present, the evaluation system of government supervising society organizations pension service has matured in abroad [1], but the international standard is not completely suitable for China's national conditions. While domestic scholars to study the government purchase pension service quality supervision and evaluation is still in the initial stage. These studies most focus on reference and comparison of the developed countries pension service government regulatory evaluation [2], or qualitative propose effective measures for supervising the quality of the government to purchase pension service [3] and so on. Some scholars have tried to construct a pension service quality evaluation model [4], but the model of quantitative evaluation index system is still not a unified standard, evaluation methods are also inconsistent.

In view of this, this paper is combined with actual cases of the Chinese typical city governments purchase pension service, and on this basis, analyzing the present situations advantages and disadvantages of social organizations provide pension service quality supervision and evaluation in actual operation. The developed countries mature management experience for reference, using the theory of system engineering to construct suitable for Chinese government purchase pension service quality management factors index system from four aspects, which is the life care services, physical and mental health services, leisure and recreation services and safety and hygiene services, and to evaluate each factor priority of the index system's criterion layer and the index layer with quantitative fuzzy comprehensive method.

\section{INDEX SYSTEMS}

Scientific and reasonable monitoring and evaluation of the pension service quality, for guarantee elderly pension life quality, improve allocation efficiency of the public service 
resource, and perfect the pension service management processes, thus promoting the development of social organizations, has a very important practical significance. At the same time, construction of government purchase pension service quality management effectiveness index system and fuzzy comprehensive evaluation model, the use of management science, economics theory and method to the field of public service, is the new development of public management theory and research methods, have a higher theoretical significance.

According to the diversity and particularity needs of the elderly pension service, consider timeliness, persistence, staff attitude and technical level of the service provider, in the current stage, success cases of China's local government purchase pension service as the basis, application service quality evaluation theory and the theory of systems engineering analysis methods, under the guidance of the scientific, systematic and feasible principles, innovatively establish the government purchase pension service quality management effectiveness index system (Fig.1) supported by the life care services, physical and mental health services, leisure and recreation services and safety and hygiene services four criteria.

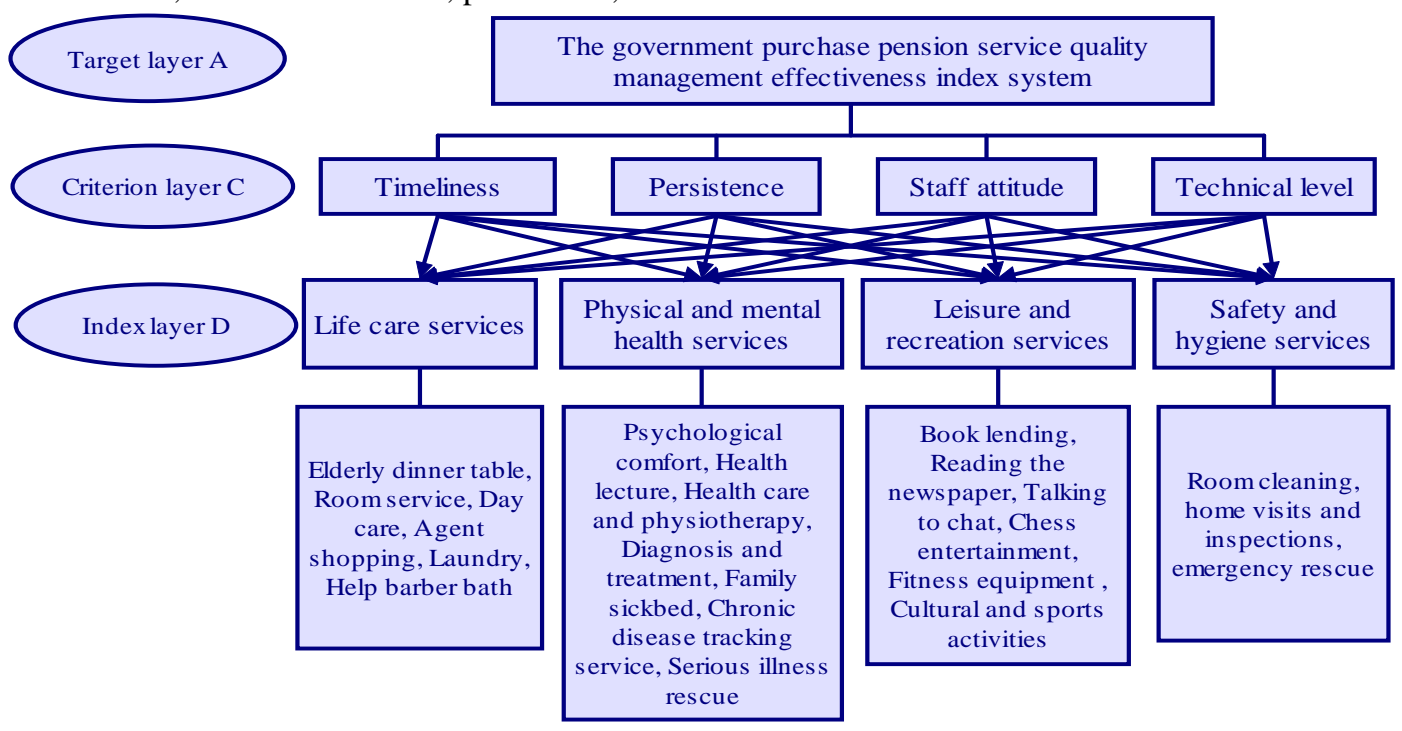

Figure1. The government purchase pension service quality management effectiveness index system

\section{COMPREHENSIVE EVALUATION}

Usually, we use the methods like analytic hierarchy process (AHP), three scale method (TMP), utility theory and so on, to solve a multi-objective decision question. However, practice proves that the above several methods in dealing with multi-objective decision-making problem have some defects.

When we use AHP methods to evaluate index quantification, the comparative rank reaches nine. And the indexes are easy to appear contradiction phenomenon. Meanwhile, there were significant differences between the consistency of AHP judgment matrix and the consistency of the human mind. Therefore, in initial comparative value requires repeated adjustment. In a word, this method's operation is so complex, and the objectivity is poorer. Three scale method (TMP) although improved AHP defect that comparative levels are too much, but the consistency inspection effect is still insufficient ideal, and the calculation work is also bigger. The last method, utility theory is complex in determining the utility function, and this method is influenced by subjective factors. Besides, the decision results are credibility poor [5].
The non-structural fuzzy decision support system (NSFDSS) method overcomes the shortcomings of all three above methods. The judgment matrix of this method is same like the construction of human thought. Second, the matrix judging processing to test the consistency is relatively simple. In the basis that the system is decomposed and comprehended, this method makes full use of human experience and knowledge, compares and quantifies large complex qualitative factors such as common importance, superiority. Finally we can get all the factors membership degree. This evaluation method suits for complicated social and economic fields and engineering technology fields that is difficult to direct quantitatively. And it can improve expert analysis judgment, reduce the difficulty of comparative judgment, improve the accuracy of solving problems, and draw an objective comprehensive evaluation conclusion more powerful [6].

Evaluation of government purchase pension service quality management effectiveness can be divided into the following four basic steps with the non-structural fuzzy decision support system (NSFDSS) method:

The first step: build hierarchical structure of the government purchase pension service quality management effectiveness decisions. 
According to established government purchase pension service quality management effectiveness index system, we group the factors it contains, and line up these groups with target layer, criterion layer and index layer. Target layer is generally expresses decision-making goal, that sorting decision-making importance of government purchase pension service quality management effectiveness. Criterion layer $\left(C_{n}\right.$ ) generally expresses decision-making criteria or constraint. This paper selects timeliness 、 persistence 、 staff attitude and technical level for four criteria. Index layer $\left(D_{m}\right)$ means the decision, corresponding to the criteria layer by life care services, physical and mental health services, leisure and recreation services and safety and hygiene services four decision-making set .

The decision criterion set of non- structural fuzzy decision support system is:

$$
\begin{aligned}
& C=\left\{c_{1}, c_{2}, \ldots, c_{n}\right\}=\left\{c_{1}, c_{2}, \ldots, c_{4}\right\} \\
& \text { Where } c_{i} \text { is ith criteria, } \mathrm{i}=1,2, \cdots, 4 .
\end{aligned}
$$

The decision index set of non- structural fuzzy decision support system is:

$$
D=\left\{d_{1}, d_{2}, \cdots, d_{m}\right\}=\left\{d_{1}, d_{2}, \cdots, d_{4}\right\}
$$

Where ${ }^{d}{ }_{j}$ is jth decision, $\mathrm{j}=1,2, \cdots, 4$.

The second step: make sure the consistency judgment matrix that government purchase pension service quality management effectiveness of decision-making.

Give judgment in the mutual importance of each element of criterion layer and index layer. Judge results should be presented numbers. And the so-called Judgment matrix is written by matrix. Judgment matrix says the relative importance of judgment between this level's related elements and a level according to it.

First, structural constraint criterion $\mathrm{C}_{\mathrm{i}}$ 's judgment matrix ${ }_{i} E$, to determine the constraint criterion $\mathrm{C}_{\mathrm{i}}$ of qualitative sort decision sets, and for all constraint factors $C_{i}$ are binary comparison, get judgment matrix. Set all criteria for pair-wise comparison and compute the matrix. So the same evaluation is done five times .Among them, four for comparing the decision index $D_{\mathrm{m}}$ under each criterion $\mathrm{C}_{\mathrm{n}}$ and one for comparing the four criteria.

$$
\begin{aligned}
& { }_{i} E=\left[\begin{array}{cccc}
{ }_{i} e_{11} & { }_{i} e_{12} & \cdots & { }_{i} e_{1 n} \\
{ }_{i} e_{21} & { }_{i} e_{22} & \cdots & { }_{i} e_{2 n} \\
\cdots & \cdots & \cdots & \cdots \\
{ }_{i} e_{n 1} & { }_{i} e_{n 2} & \cdots & { }_{i} e_{n n}
\end{array}\right]=\left({ }_{i} e_{k l}\right) \\
& { }_{i} e_{k l}=\left\{\begin{array}{ccc}
0 & v_{l} & \text { better than } v_{k} \\
0.5 & v_{l} & \text { same as } v_{k} \\
1 & v_{k} & \text { worse than } v_{l}
\end{array}\right.
\end{aligned}
$$

Where $\mathrm{k}=1,2 \ldots \mathrm{n} ; \mathrm{l}=1,2 \ldots \mathrm{n}$

Then the priority matrix ${ }_{i} E$ is checked for consistency by the following condition:

$$
\left\{\begin{array}{lrl}
\text { when } \quad{ }_{i} e_{h k}>{ }_{i} e_{h l} & { }_{i} e_{k l}=0 \\
\text { when } \quad{ }_{i} e_{h k}<{ }_{i} e_{h l} & { }_{i} e_{k l}=1 \\
\text { when }{ }_{i} e_{h k}={ }_{i} e_{h l}=0.5 & { }_{i} e_{k l}=0.5
\end{array}\right.
$$

There are five detailed conditions to check whether matrix ${ }_{i} E$ satisfies the consistency checking of priority ordering. They are: If ${ }_{i} e_{h k}>{ }_{i} e_{h l},{ }_{i} e_{k l}=0$; If ${ }_{i} e_{h k}<{ }_{i} e_{h l},{ }_{i} e_{k l}=1$; If ${ }_{i} e_{h k} \quad={ }_{i} e_{h l}=0.5 \quad, \quad{ }_{i} e_{k l}=0.5$; If $\quad{ }_{i} e_{h k} \quad=_{i} e_{h l}=1$, ${ }_{i} e_{k l}=\left\{\begin{array}{lll}0 & 0.5 & 1\end{array}\right\} ;$ If $_{i} e_{h k}=e_{i} e_{h l}=0,{ }_{i} e_{k l}=\left\{\begin{array}{lll}0 & 0.5 & 1\end{array}\right\}$.

After consistency checking, the matrix must meet the transitivity of priority sort, so ${ }_{i} E$ is called consistency scale matrix of priority sort. According to the consistency priority sort, the elements of pair-wise comparison matrix ${ }_{i} E$ are rearranged in a descending order.

The five output matrices are generated for further evaluation as follows in Fig. 2.

\begin{tabular}{|c|c|c|c|c|c|}
\hline $\mathrm{C} 1$ & $\mathrm{~d} 1$ & $\mathrm{~d} 2$ & $\mathrm{~d} 3$ & $\mathrm{~d} 4$ & Row Total \\
\hline $\mathrm{d} 1$ & 0.5 & 0 & 1 & 1 & 2.5 \\
\hline $\mathrm{d} 2$ & 1 & 0.5 & 1 & 1 & 3.5 \\
\hline $\mathrm{d} 3$ & 0 & 0 & 0.5 & 0 & 0.5 \\
\hline $\mathrm{d} 4$ & 0 & 0 & 1 & 0.5 & 1.5 \\
\hline $\mathrm{C} 2$ & $\mathrm{~d} 1$ & $\mathrm{~d} 2$ & $\mathrm{~d} 3$ & $\mathrm{~d} 4$ & Row Tota1 \\
\hline $\mathrm{d} 1$ & 0.5 & 1 & 1 & 1 & 3.5 \\
\hline $\mathrm{d} 2$ & 0 & 0.5 & 1 & 1 & 2.5 \\
\hline $\mathrm{d} 3$ & 0 & 0 & 0.5 & 0.5 & 1 \\
\hline $\mathrm{d} 4$ & 0 & 0 & 0.5 & 0.5 & 1 \\
\hline
\end{tabular}

\begin{tabular}{|c|c|c|c|c|c|}
\hline $\mathrm{C} 3$ & $\mathrm{~d} 1$ & $\mathrm{~d} 2$ & $\mathrm{~d} 3$ & $\mathrm{~d} 4$ & Row Total \\
\hline $\mathrm{d} 1$ & 0.5 & 1 & 1 & 1 & 3.5 \\
\hline $\mathrm{d} 2$ & 0 & 0.5 & 1 & 1 & 2.5 \\
\hline $\mathrm{d} 3$ & 0 & 0 & 0.5 & 1 & 1.5 \\
\hline $\mathrm{d} 4$ & 0 & 0 & 0 & 0.5 & 0.5 \\
\hline
\end{tabular}

\begin{tabular}{|c|c|c|c|c|c|}
\hline $\mathrm{C} 4$ & $\mathrm{~d} 1$ & $\mathrm{~d} 2$ & $\mathrm{~d} 3$ & $\mathrm{~d} 4$ & Row Tota1 \\
\hline $\mathrm{d} 1$ & 0.5 & 0 & 0.5 & 0.5 & 1.5 \\
\hline $\mathrm{d} 2$ & 1 & 0.5 & 1 & 1 & 3.5 \\
\hline $\mathrm{d} 3$ & 0.5 & 0 & 0.5 & 0.5 & 1.5 \\
\hline $\mathrm{d} 4$ & 0.5 & 0 & 0.5 & 0.5 & 1.5 \\
\hline
\end{tabular}

\begin{tabular}{|c|c|c|c|c|c|}
\hline $\mathrm{A}$ & $\mathrm{c} 1$ & $\mathrm{c} 2$ & $\mathrm{c} 3$ & $\mathrm{c} 4$ & Row Tota1 \\
\hline $\mathrm{c} 1$ & 0.5 & 1 & 1 & 0.5 & 3 \\
\hline $\mathrm{c} 2$ & 0 & 0.5 & 0.5 & 0 & 1 \\
\hline $\mathrm{c} 3$ & 0 & 0.5 & 0.5 & 0 & 1 \\
\hline $\mathrm{c} 4$ & 0.5 & 1 & 1 & 0.5 & 3 \\
\hline
\end{tabular}

Figure.2 Output matrices after consistency check 
The third step: make sure and rank the weightings of government purchase pension service quality management effectiveness judgment matrix.

After the consistency check, the values of indicators on each row are summed up. The priority score is calculated by the method used in reference [7]. The magnitude of the pairwise comparison by assigning weightings to these decision criteria is measured (Fig.3).

$$
r_{i j}=\frac{1-{ }_{i} a_{1 j}}{{ }_{i} a_{1 j}}
$$

Where ${ }^{i a_{1 j}}$ is the semantic score, $0.5 \leq_{i} a_{1 j} \leq 1$ (0.5=same, 1=different).

\begin{tabular}{|c|c|c|c|c|}
\hline$R_{i j}$ & $c 1$ & $c 2$ & $c 3$ & $c 4$ \\
\hline$d 1$ & 0.333 & 0.333 & 0.5 & 0.167 \\
\hline $\mathrm{d} 2$ & 0.5 & 0.222 & 0.333 & 0.5 \\
\hline $\mathrm{d} 3$ & 0 & 0.222 & 0.167 & 0.167 \\
\hline $\mathrm{d} 4$ & 0.167 & 0.222 & 0 & 0.167 \\
\hline
\end{tabular}

Figure.3 Priority ordering of semantic score;

The weightings of criteria are calculated in the same way. The weightings set of decision criteria priority scores are: $W^{\prime}=\left(w_{1}^{\prime}, w^{\prime}{ }_{2}, \cdots, w^{\prime}{ }_{m}\right) \quad$ and $W_{1}^{\prime}=1$. After $W_{1}^{\prime}$ is normalized, the weightings set of decision criteria is acquired (Fig.4).

$$
W=\left(w_{1}, w_{2}, \cdots, w_{m}\right), \sum_{i=1}^{m} w_{i}=1
$$

\begin{tabular}{|c|c|c|c|c|}
\hline & c1 & c2 & c3 & c4 \\
\hline W' & 0.833 & 0.167 & 0.167 & 0.833 \\
\hline W & 0.417 & 0.084 & 0.084 & 0.417 \\
\hline
\end{tabular}

Figure.4 Calculation results of centralization vector in criterion factors

The fourth step: determination of the evaluation results.

The contribution of each decisions $\left(S P_{i j}\right)$ is calculated after knowing the weightings of each decision criteria. It is calculated by following formula.

$$
S P_{i j}=w_{i} \times r_{i j}, \sum_{i=1}^{n} \sum_{j=1}^{m} S P_{i j}=1
$$

Among them, $\mathrm{n}$ means criteria number, $\mathrm{m}$ means the decision-making number. The comprehensive calculation result $S P_{i j}$ is presented as follows:

\begin{tabular}{|c|c|c|c|c|c|}
\hline $\mathrm{SP}_{\mathrm{i} j}$ & $\mathrm{c} 1$ & $\mathrm{c} 2$ & $\mathrm{c} 3$ & $\mathrm{c} 4$ & Row Tota1 \\
\hline $\mathrm{d} 1$ & 0.139 & 0.028 & 0.042 & 0.07 & 0.279 \\
\hline $\mathrm{d} 2$ & 0.209 & 0.019 & 0.028 & 0.209 & 0.465 \\
\hline $\mathrm{d} 3$ & 0 & 0.019 & 0.014 & 0.07 & 0.103 \\
\hline $\mathrm{d} 4$ & 0.07 & 0.019 & 0 & 0.07 & 0.159 \\
\hline
\end{tabular}

Figure.5 The ranking of superiority calculation results in decision sets

Repeat the above steps to evaluate criteria layer comprehensive evaluation results of each index factors under the sub-index set module. We can get the final conclusion. In the application of the government purchase pension service quality management effectiveness decision, physical and mental health services is need to be paid close attention, later it was life care services, safety and hygiene services and leisure recreation services sequentially.

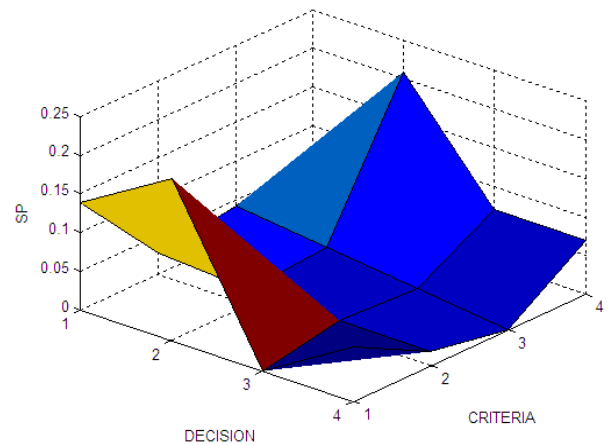

Figure.6 The three-dimensional graph of comprehensive evaluation result

\section{CONCLUSION}

Apply this model and evaluation conclusions obtained a comprehensive evaluation of the results of a threedimensional diagram is shown in Fig 6. Comprehensive evaluation of government purchase pension service quality management performance, publish regular supervision and evaluation results to social, so that service providers to amend and improve the existing supervision and management problems in time, can effectively improve the efficacy of pension services, complete the pension services regulatory processes, and provide support for the system science theory of government purchase pension service management mechanism.

\section{REFERENCES}

[1] Parasuraman A, Zeithaml VA, and Berry LL, "A Conceptual Model of Service Quality and Its Implication for Future Research”[J]. Journal of Marketing. 1985, 49(Fall) : pp.41- 50.

[2] Wang Lifang. “Japanese pension service evaluation system and its impact on our caring service implications” [J]. Journal of Zhaoqing University, 2010, (4) : pp.45 - 50 .

[3] Han Yutien. "Research on the problems and policies of pension service in community" [D] . Shanghai: East China University of Science and Technology School of social and public management, 2011: pp. 29 - 30.

[4] KZhang Xiaoyi,Liu Bangcheng. "Research on quality model of community home endowment service : Based on SERVQUAL perspective” $[\mathrm{J}]$ 。China's population science, 2011 (3) pp.:83-92..

[5] Yang FengShou and Hu XiaoYun, "Improve on the basis of three graduation infantry element of method is it fight determined scheme appraise to land. Command controlling and emulation . (2009) 48-51..

[6] C.M.Tam, Thomas K.L.Tong and Gerald C.W.Chiu, "Non-structural fuzzy decision support system for evaluation of construction safety management system”. International Journal of Project Management. (2002)Vol 20.303-313.

[7] Chen SY, Engineering fuzzy set theory and application. Beijing State Security Industry Press. (1998). 